\title{
EM BUSCA DA PROFICIÊNCIA CONCEITOS, CONCEPÇÕES E IDEIAS SOBRE LEITURA
}

\author{
Cleonice Nogueira Ferraz Porpino Estruc ${ }^{1}$
}

\section{RESUMO}

O conhecimento de estratégias no ensino de leitura e o uso de atividades que fomentem o ato de ler apresentam-se como práticas pedagógicas primordiais exercidas pelos professores ao longo da educação básica. Dessa forma, o estudo que aqui se consubstancia em forma de artigo tem o escopo de detalhar conceitos, concepções e ideias sobre leitura em prol de uma proficiência leitora. Tal meta surge face ao problema da não percepção da importância de ações de fomento à leitura nos espaços escolares e da pouca credibilidade e raro reconhecimento por parte da sociedade para o universo leitor. Assim, espera-se que este levantamento bibliográfico sirva de embasamento teórico para estudos posteriores e que atuem em prol de ações que democratizem e valorizem a leitura como algo inerente à ação humana.

Palavras-chave: Leitura; Proficiência Leitora; Espaços Escolares.

\section{RESUMEN}

El conocimiento de las estrategias en la enseñanza de la lectura y el uso de actividades que promueven el acto de la lectura se presentan como prácticas pedagógicas primordiales ejercidas por los docentes a lo largo de la educación básica. Por lo tanto, el estudio que se plasma aquí en la forma de un artículo tiene el alcance de detallar conceptos, concepciones e ideas sobre la lectura en favor de una competencia lectora. Este objetivo surge en vista del problema de la no percepción de la importancia de las acciones para promover la lectura en los espacios escolares y la poca credibilidad y el raro reconocimiento por parte de la sociedad para el universo lector. Así, se espera que este estudio bibliográfico sirva de base teórica para estudios posteriores y que actúen a favor de acciones que democraticen y valoren la lectura como algo inherente a la acción humana.

Palabras clave: Lectura; Competencia del lector; Espacios Escolares.

\begin{abstract}
The knowledge of strategies in reading teaching and the use of activities that promote the act of reading are presented as primordial pedagogical practices exercised by teachers throughout basic education. Thus, the study that is embodied here in the form of an article has the scope of detailing concepts, conceptions and ideas about reading in favor of a readeric proficiency. This goal arises in view of the problem of not perception of the importance of actions to promote reading in school spaces and the little credibility and rare recognition by society for the reading universe. Thus, it is expected that this bibliographic survey will serve as a theoretical basis for later studies and that they act in favor of actions that democratize and value reading as something inherent to human action.
\end{abstract}

Keywords: Reading; Reader Proficiency; School Spaces.

\footnotetext{
${ }^{1}$ Mestre em Ciências da Educação pela Universidad Autónoma de Assunción - Paraguai

E-mail: cleoestruc@hotmail.com
} 


\section{INTRODUÇÃO}

Importante começar uma investigação em uma base conceitual mais elementar, neste caso, inicia-se com a conceituação da palavra ler. Derivada do latim, ler teve um significado originário da agricultura, pois legere queria dizer primitivamente "colher, escolher, recolher", denotando que as pessoas selecionam e retiram da árvore os melhores frutos, os melhores cachos. No sentido atual, significa obter informações através da percepção das letras, pois indica uma capacidade de escolher e definir corretamente letras e palavras. É equivalente à expressão latina legere oculis, ou seja, colher com os olhos. Nesse sentido, a leitura também é entendida como uma colheita de utilidades e prazeres que acompanham a pessoa pela vida afora.

Conhecer, portanto, a origem, o significado e o emprego correto das palavras no ensino da língua oficial, deve estar entre as inúmeras atividades trabaIhadas pelo professor em situação didática. Como o ensino da leitura vai além dos conteúdos curriculares, englobando os vários tipos de leitura e de ambientes de leitura, tipos de leitor, ferramentas de leitura e usos, e o valor e as vantagens da leitura, deve-se ter em mente que os conhecimentos que visam tornar o aluno um leitor proficiente devem estar à frente das ações docentes.

Para tanto, o conhecimento de estratégias no ensino de leitura e o uso de atividades voltadas para esse fim apresentam-se como práticas pedagógicas primordiais exercidas pelos professores no fomento ao ato de ler. É importante, assim, que o professor esteja atento para, de acordo com Sandoval (2008, p. 379), conhecer as disfunções ou erros que se cometem quando se lê, e é necessário tratar de corrigi-los, se se tem, já que pode afetar a velocidade e a compreensão leitora. Também se deve tratar da importância de utilizar-se de técnicas e exercícios que ajudem a melhorar os níveis de leitura, a quantidade, a qualidade e, consequentemente, o rendimento do aluno. (SANDOVAL, 2008, p. 380)

Dessa maneira, o presente artigo busca detalhar conceitos, concepções e ideias sobre leitura em prol de uma proficiência leitora. Com uma vertente essencialmente bibliográfica, esse estudo pretende contribuir para a comunidade científica e consubstanciar pesquisas na área da linguagem e disciplinas afins. Para tal, este estudo divide-se em Tipos de leitura; Ambientes de leitura e a 


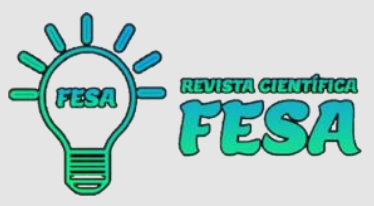

questão das bibliotecas escolares; Tipos de Leitores e Leitores Proficientes; Leitor Contemplativo, Meditativo; Leitor Movente, Fragmentado; Leitor Imerso, Virtual; e Leitor Proficiente.

\section{TIPOS DE LEITURA}

Os vários tipos de leitura discutidos a seguir estão de acordo com a classificação apresentada por Hernández Pina (1998, p. 52). A leitura oral, por exemplo, é a que se faz em voz alta, é a primeira que se pratica quando se aprende a ler. A aprendizagem da leitura oral não é fácil, pois se supõe aprender não somente a ler as palavras, senão também a modular nossa voz.

Para teóricos como Secco (2003, p. 19), essa prática só deveria ocorrer para o treinamento da fala e da estética literária, nunca para treinar a leitura em si. Isso porque, quando um aluno for solicitado a ler na frente da classe, ele precisará de toda sua autoestima para passar por cima do nervosismo, do frio na barriga e da possibilidade de errar na frente de todos, o que, sem dúvida, costuma ocorrer. Além disso, a leitura oral leva o aluno a ler sem perceber, palavra por palavra, não conseguindo assim transmitir o significado real do texto, o que faz com que nem ele nem os demais alunos compreendam efetivamente o que foi lido. Aliás, muitas vezes, a maioria das crianças não prestam nenhuma atenção ao que está sendo proferido.

Estudos já demonstraram que a leitura oral e a silenciosa ativam regiões distintas do cérebro. Sobre essa, afirma-se que a leitura silenciosa se faz sem expressar de viva voz o que se está lendo. É o tipo de leitura mais frequente, seu uso é sempre pessoal.

Para Secco (2003, p. 20), esse tipo de leitura é muito mais eficiente, pois compreendemos melhor quando lemos em silêncio. E, como seremos leitores silenciosos na maior parte das vezes durante toda nossa vida, esse tipo deveria ter predomínio na sala de aula.

Em acréscimo, Hernández Pina (1998, p. 52) cita que a leitura exploratória consiste em ler um texto rapidamente, buscando as ideias ou a informação que nos interessa e a leitura recreativa pressupõe uma leitura silenciosa, mas caracteriza-se por ser utilizada quando se lê por prazer, ou seja, a velocidade com que se faz sugere ser rápida. 


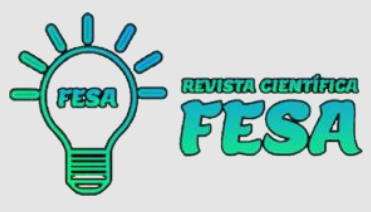

Há, ainda, leitura palavra a palavra que se materializa quando o material que se tem que ler exige fazê-lo com muito detalhe. Assim, este tipo de leitura somente ocorre quando se lê um problema de matemática ou palavra em uma língua estrangeira. No mesmo intento, há a leitura focada no estudo que sugere ser lenta e requer muita atenção.

Por fim, a leitura crítica visa avaliar a relevância do que se lê, sendo um tipo mais cuidado, reflexivo, compreensivo, enfim, trata-se de uma leitura funcional, cuja exigência é não ser muito rápida.

Sertillanges (2010, p. 124) distingue, de modo complementar, quatro espécies de leitura, afirmando que se lê para ter uma formação e ser alguém; lê-se em vista de uma tarefa; lê-se como treinamento para o trabalho e para o bem; lê-se por ser uma distração. Há, então, leituras fundamentais, leituras ocasionais, leituras de treinamento ou edificantes, leituras relaxantes.

Nesse sentido, a leitura crítica, a enfocada no estudo, a da palavra a palavra e a leitura recreativa têm a ver com o uso ou funcionalidade que se faz delas, enquanto a leitura oral, a leitura silenciosa e a leitura exploratória correspondem a uma categoria distinta que tem a ver com a maneira de manifestar-se do leitor.

Ao discorrer sobre a diferença entre ensino e descoberta, Adler e Van Doren $(2015$, p. 35) diz que é, provavelmente, verdade que pensamos menos quando lemos para nos informar ou para nos divertir do que quando nos esforçamos para descobrir algo. São os tipos de leituras menos ativos que existem, porém isso não é verdade no que se refere à leitura ativa, ou seja, ao esforço para entender. Ninguém que tenha empreendido esse tipo de leitura diria que se trata de uma atividade fácil, pois demanda muita dedicação.

Manguel (2010, p. 75), ao escrever sobre o aprendizado da leitura, diz:

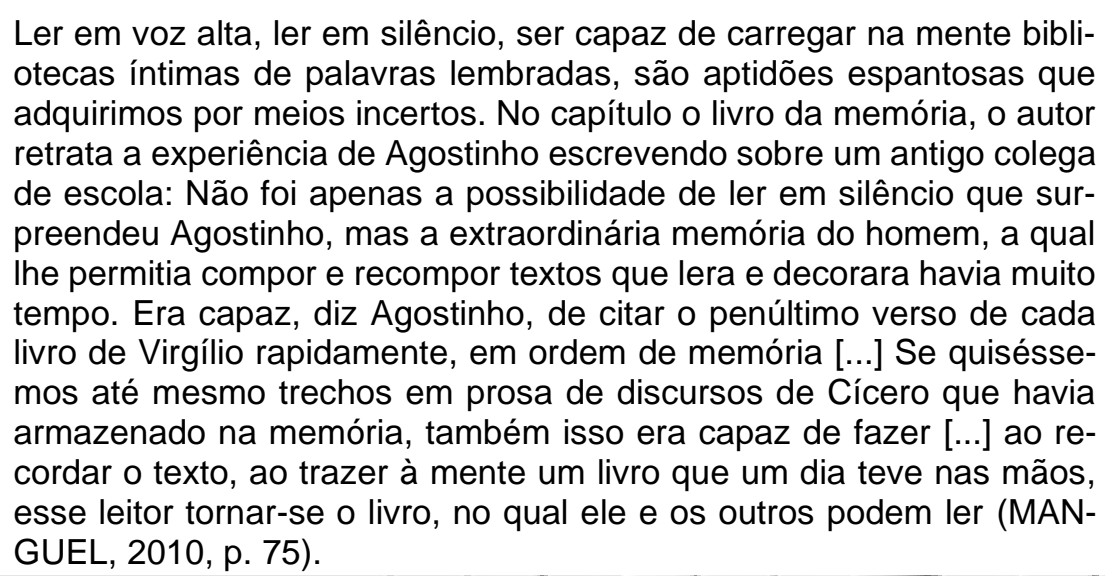


Todavia, continua o autor, antes que essas aptidões possam ser adquiridas, o leitor precisa aprender a capacidade básica de reconhecer os signos comuns pelos quais uma sociedade escolheu comunicar-se: em outras palavras, 0 leitor precisa aprender a ler. Ainda, citando a experiência vivida por Claude LéviStrauss, durante sua temporada entre os nhambiquaras no Brasil, para o antropólogo que aprendera a ler numa escola europeia, a noção de que um sistema de comunicação pudesse ser imediatamente compreensível a qualquer outra pessoa parecia absurdo.

Os métodos pelos quais aprendemos a ler não só encarnam as convenções da nossa sociedade em relação à alfabetização - a canalização da informação, as hierarquias de conhecimento e poder -, como também determinam e limitam as formas pelas quais nossa capacidade de ler é posta em prática. Em todas as sociedades letradas, aprender a ler tem algo de iniciação, de passagem ritualizada para fora de um estado de dependência e comunicação rudimentar, conclui Manguel (2010, p. 85 e 89).

O que se percebe é que esse estado de dependência ainda é uma realidade entre muitos alunos das séries finais do ensino fundamental em escolas públicas brasileiras, falta-lhes condições de processar informações, motivação e interesse para avançar na aprendizagem da leitura.

Segundo Salla (2012), para o estímulo provocar certa resposta, é necessário que o indivíduo e seu organismo sejam capazes de fornecê-la. Por isso, não basta ter um meio provocativo se a pessoa não participar dele, se for incapaz de sensibilizar com os estímulos oferecidos e reagir a eles (SALLA, 2012, p. 54).

Partindo dessas concepções, alguns questionamentos podem ser construídos, como, por exemplo, será que nossas escolas apresentam estratégias de ensino capazes de despertar o interesse e sensibilidade do aluno para a importância e necessidade da leitura? Será que os leva a perceberem que quem não lê enxerga o mundo com os olhos de outrem?

Quem acredita no que ouve e não constrói parâmetros próprios para analisar o mundo a partir de diferentes perspectivas está, lamentavelmente, atrelado ao físico, ao material, deixando de utilizar a capacidade que mais caracteriza o ser humano: a abstração, e tendo dificuldade de operar na ausência do objeto, afirma Bozza (2008, p. 24). 


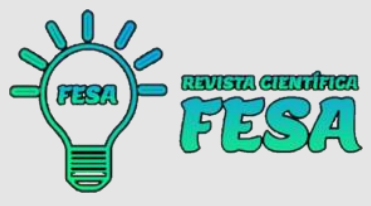

Ainda, para Manguel (2010):

[...] os humanistas da Idade Média tardia, o texto (incluindo a leitura que fez Platão do argumento socrático, onde Sócrates afirmava que somente o que o leitor já conhece pode ganhar vida com uma leitura, e, para ele, o conhecimento não pode ser adquirido com letras mortas) e os sucessivos comentários das diversas gerações de leitores implicavam tacitamente que era possível haver não apenas uma, mas um número quase infinito de leituras, todas alimentando-se reciprocamente. Nossa leitura em sala de aula do discurso de Lísias recebeu a contribuição de séculos dos quais Lísia jamais suspeitou - assim como não poderia fazer ideia do entusiasmo de Fedro ou dos comentários astuciosos de Sócrates. O livro na minha estante não me conhece até que eu o abra, e, no entanto, tenho certeza de que ele se dirige a mim - a mim e a cada leitor - pelo nome; está à espera de nossos comentários e opiniões. Eu estou pressuposto em Platão, assim como cada livro me pressupõe, mesmo aqueles que nunca lerei. (MANGUEL, 2010, p. 106).

Essa reflexão apresentada por Manguel (2010, p. 106) na citação anterior chama a atenção para a forma como a leitura e o seu principal instrumento sistematizado, o livro, têm sido tratados nas escolas públicas brasileiras.

Há centenas de livros trancados em bibliotecas escolares, adormecidos em suas estantes empoeiradas, além da má utilização do livro didático dos diversos componentes curriculares, adquiridos para o aluno, esperando para serem utilizados para estudos em sala de aula e em casa, de modo a que os conteúdos fossem aprofundados através de pesquisa em outras fontes e em outros espaços de leitura, como é o caso dos acervos das bibliotecas das escolas, que deveriam estar à disposição de alunos, dos professores e, também, da comunidade.

Além disso, é responsabilidade da escola na atualidade dispor de acervos impressos para leitura, empréstimo e pesquisa, de bibliotecas equipadas com novos recursos como tablets e laptops e, principalmente, conectadas à internet. Ou seja, com a digitalização crescente de textos e imagens, artigos, jornais, revistas ou livros inteiros, o que anteriormente apenas podia ser lido na forma impressa pode agora, complementarmente ou em alternativa, ser lido numa tela de computador, seja pela internet, em um CD-ROM ou em outro aparelho que permita a leitura em suporte digital (BELLO, 2002).

Com a crescente e inovadora mudança dos suportes de leitura, mudam não só os tipos de leituras e de leitores, também se alteram a forma de ensinar dos professores e a estrutura das escolas, para que se possam disponibilizar aos diversos segmentos da comunidade escolar. 


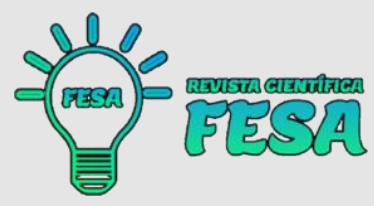

Como afirma Carneiro (2008), a variedade dinâmica de portadores de texto que a tecnologia contempla e contribui para com o interesse de qualquer público. Assim, a vivência em inúmeras situações de leitura permite definir qual gênero ler e se conhecer as características individuais e a oportunidade de ler está vinculada à disponibilidade e à variedade de livros e a tecnologia digital se caracteriza por essa diversidade.

A autora também apresenta alguns exemplos de situações de leitura que contemplam as seguintes ações:

Leitura orientada no ambiente virtual; Leitura livre no ambiente virtual; promoção de debate: Lendo no livro impresso e no livro digital: quais as diferenças?; averiguação das preferências dos gêneros literários; participação ativa no blog criado; Confecção de um livro e disponibilização deste no ambiente virtual". (CARNEIRO, 2008).

A leitura digital também é respaldada por Ferreiro (2008), quando destaca que a presença da escrita na tela do computador é hoje um fato universal. A tecnologia da informação e da comunicação está trazendo mudanças importantes não apenas no mercado de trabalho, mas também nas práticas de leitura e escrita.

É fato que a tecnologia digital hoje está presente nos mais diversos espaços e momentos da vida e de forma muito especial nos usos das leituras, necessárias à formação de crianças e jovens em fase de aquisição e de transformação do conhecimento de forma sistematizada.

Dessa maneira, é papel da escola, através dos seus educadores, a orientação dos educandos quanto ao aprendizado de critérios necessários à seleção dos textos a serem lidos e frente à imensa diversidade de leitura existente. É uma preocupação de educadores, como Ferreiro (2008), ao enfatizar que a escola não valoriza as habilidades de seleção - eleger o que serve e o que não serve - e que é responsabilidade da escola pôr as crianças em contato com o que haja de melhor em seu tempo. Apenas filtrar todo o universo virtual é, por fim, uma missão que só se faz valer se o leitor souber definir critérios para a seleção do que vai ler. 


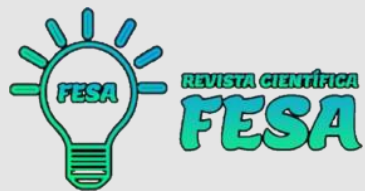

F[5

\section{AMBIENTES DE LEITURA E A QUESTÃO DAS BIBLIOTECAS ESCOLARES}

Partindo do pressuposto de que a leitura pode ser um hobby, cabe a cada leitor eleger o melhor lugar para se entregar à leitura dos livros ou fazê-lo de acordo com o ambiente em que se encontre, tais como ler deitado antes de dormir, na cama ou no sofá, ler a caminho da escola ou do trabalho, no ônibus ou no metrô, ler em viagem, na praia, embaixo de uma árvore, entre outros. O aluno que tem o hábito da leitura busca os próprios cantos e lê.

$\mathrm{Na}$ escola, além da sala de aula, é a biblioteca o espaço pedagógico, cultural e social, por excelência, responsável pela realização de ações que visem ao incentivo, à divulgação e à prática da leitura. Sua função principal é dispor de meios para expandir o conhecimento do estudante e do professor, além de dispor dos vários tipos de leitura e de recursos a serem utilizados no incentivo à pesquisa, à leitura formativa e ao lazer.

Para tanto, precisam dispor de uma escola adequada, uma sala de aula equipada e uma biblioteca com boa estrutura física, com ambientes que sejam funcionais e ter recursos humanos capacitados com condições de exercer suas funções.

Para que a biblioteca escolar cumpra o seu papel social dentro da sociedade do conhecimento, faz-se necessária a funcionalidade de todos os elementos que a compõem como acervos atualizados e novas tecnologias que atendam às necessidades e aos interesses daquele público-alvo, mobiliários e equipamentos adequados, atualizados e em número suficiente, profissionais qualificados e em condições de exercício de suas funções, espaço amplo, com boa iluminação, ventilação, acessível e com sinalização).

Somam-se, a esses elementos, a valorização, a formação, a atualização e o compromisso dos responsáveis por esse espaço. Martins (2009), sobre isso, relata que:

Apesar de não ser o responsável pela organização das prateleiras, cabe ao professor conhecer a variedade de títulos e materiais disponível nas bibliotecas escolares para, com um planejamento eficiente e estratégias pensadas, enriquecer o ensino dos conteúdos curriculares. (MARTINS, 2009). 


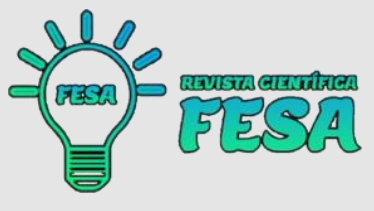

O autor indica, inclusive, seis estratégias fundamentais para utilizar a biblioteca de forma mais eficaz com a turma, tais como conhecer os materiais é a chave para planejar o trabalho; difundir o uso da biblioteca dentro e fora da escola; ensinar a pesquisar para fortalecer a autonomia; expor a produção dos alunos; ler por prazer em casa, na escola, só ou acompanhado; e dar mais livros para mais bibliotecas.

Conforme propõe Martins (2009), o docente deve procurar saber quais são suas possibilidades para sua disciplina. Essa etapa vai facilitar a discussão sobre o formato e o papel das atividades. Nessa linha de entendimento, o mesmo autor, destaca sobre a importância do papel e da utilização da biblioteca pelo professor e pelo aluno, citando que a biblioteca escolar bem utilizada funciona como uma potente ferramenta para o desenvolvimento do aluno, de sua autonomia intelectual e, também, do processo de ensino e aprendizagem.

Antunes (2010c) comenta a Lei Federal no 12.244, de 24 de maio de 2010, que dispõe sobre a universalização das bibliotecas nas instituições de ensino do país, obrigando a existência de bibliotecas em todas as escolas. Ela considera um grande avanço, ainda que o tempo previsto para a adequação seja grande e o acervo mínimo. Essa lei é um ganho imenso para o Brasil, é o primeiro movimento governamental a se preocupar com a questão. No entanto, a lei foi muito generosa com quem não tem e não quer ter biblioteca escolar. Ao mesmo tempo que coloca a obrigação, dá um prazo grande para que seja posta em prática e define que o tamanho mínimo do acervo seja de um livro por aluno matriculado, o que é pouco.

A recomendação das organizações que tratam do tema cita sete ou mais livros por aluno, justificando a sua preocupação ao afirmar que é tempo demasiado. O necessário é ter uma política consistente para a biblioteca escolar, porque, daqui a dez anos, os alunos de hoje já terão saído da escola. Se essa fosse uma prioridade e tivéssemos bibliotecas atuantes e integradas com a sala de aula, realmente utilizadas pelos alunos e professores e toda comunidade escolar, teríamos condições de dar um salto em índices, como o Índice de Desenvolvimento da Educação Básica (IDEB).

Outra pontual preocupação de Antunes (2010a) é com os recursos humanos que hoje atuam na biblioteca escolar. Além da carência do profissional de biblioteconomia, aportam às bibliotecas com professores ou servidores em fase 


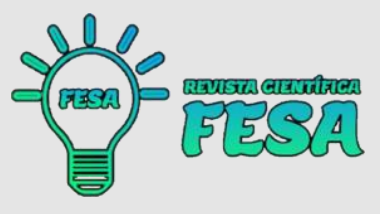

de aposentadoria, outros desviados de função por motivo de doença, ou docente com dificuldades psicológicas para atuarem em salas de aula.

É uma situação até absurda, pois a biblioteca precisa de pessoas dinâmicas, porque atende a todas as crianças, jovens, classes e professores e a um planejamento. Constitui um dos pleitos fazer com que as secretarias e os governos entendam que a função da biblioteca é tão didática e pedagógica quanto a da sala de aula.

Esse ambiente escolar deve permear todo o plano pedagógico da escola, os professores de todas as disciplinas devem ter relação com ela, pois um aluno não consegue desenvolver um problema de matemática se não for bom leitor, não souber interpretar as questões. Infelizmente, poucos têm essa visão, a maioria acha que só é do interesse dos professores de língua portuguesa e literatura.

\section{TIPOS DE LEITORES E LEITORES PROFICIENTES}

Considerando que é no ambiente escolar onde a atividade da leitura gráfica é mais exercida, ou mesmo o único contexto em que essa ação de lazer ou de enriquecimento do conteúdo é praticada, dispor esse espaço de melhores condições para tal prática deve ser medida fundamental e urgente.

Os ambientes onde reside a maioria dos alunos das escolas públicas brasileiras são de baixo letramento, é, portanto, tarefa da escola e do professor estarem atentos para identificar os principais problemas que dificultam a prática da leitura dos seus alunos. Também trabalhar com técnicas e dicas que visem à superação dessa dificuldade, isso irá ajudar o estudante a se tornar um leitor melhor.

Deve-se atentar, também, para a necessidade de conscientizar o aluno sobre a importância dessa prática e que para começar, precisa ler e ler diariamente, transformando esse ato em um hábito contínuo, não esperando tempo específico para fazê-lo e deixando a leitura sempre por último.

Ao analisar como poucos anos de idade fazem diferença na relação com a tecnologia e o que ela interfere no comportamento cotidiano de cada um, Santaella (2011) recorda uma velha leitura, em que são apresentadas ótimas definições de quatro tipos de leitores e como eles se comportam: leitor contemplativo, meditativo; leitor movente, fragmentado; leitor imerso, virtual; e leitor proficiente. 


\section{LEITOR CONTEMPLATIVO OU MEDITATIVO}

Para Santaella (2011), esse tipo de leitor é oriundo da Idade Média, onde se institui que a leitura nas bibliotecas seria feita em silêncio. Desde então, uma grande mudança ocorreu no processo de entendimento de um texto, pois, depois de séculos, a leitura passaria a ser algo muito mais íntimo e pessoal, sem a presença de um orador, sem interferências externas e apenas feita pelo movimento dos olhos e o virar das páginas. É nesse momento que nasce o leitor contemplativo.

Esse tipo de leitor se isenta de situações mundanas para se concentrar na leitura, numa atividade solitária, que pode ser interrompida para reflexão, retornada, feita novamente por dezenas de vezes até que o entendimento seja feito do modo desejado, procurando o isolamento para absorção do conteúdo, não se preocupando com quanto tempo faz que está lendo nem tem pressa para terminar. Da mesma maneira, poderiam ler quadros ou esculturas numa galeria ou admirar e perceber a arquitetura que o cerca.

\section{LEITOR MOVENTE, FRAGMENTADO}

É o tipo de leitor que surge após a Revolução Industrial, aquele que viu as locomotivas trazendo esperanças em formato de produtos produzidos em grande escala, que ganharam horários rígidos nas fábricas e que tudo isso, junto com o cinema, a luz elétrica, o telégrafo, depois os jornais, revistas e tudo que poderia cercar as pessoas com informações. (SANTAELLA, 2011).

Todos os lugares tinham textos que acendiam e apagavam nos luminosos dos estabelecimentos comerciais dos mais diversos tipos, além de cartazes de propaganda, rótulos de produtos, fachadas, automóveis, placas de sinalização. Médicos, veterinários e advogados viraram produtos também. Todo mundo, os leitores moventes, lendo tudo ao redor, rapidamente e com menos concentração e com a pressa que a vida pós-revolução industrial foi emprestando a todos. (SANTAELLA, 2011). 


\section{LEITOR IMERSO, VIRTUAL}

Embora a leitura da escrita de um livro seja sequencial, a solidez do objeto livro permite idas e vindas, retornos, ressignificações. Assim, o leitor contempla e medita à sua maneira. Santaella (2011) assim caracteriza leitor imerso, virtual como:

[...] o leitor nascente da era digital e de todas as possibilidades que os recursos técnicos e tecnológicas podem ofertar. Nada de ordem para ler. O leitor imersivo está a todo tempo em prontidão para receber e ler novas informações, traçar seu próprio caminho em navegações alineares ou multilineares [...] que passeia por várias dimensões de conteúdos [...] que entrecruza os dados com outros textos, os compara e gera um terceiro ou um quarto conteúdo. (SANTAELLA, 2011).

Porém, para Canuto (2009), na leitura do livro, essa dinâmica possibilita ao leitor conduzir a apreensão do conteúdo, adicionando sua inferência, consultando textos afins etc. Sobre a expansão da forma de ler, Canuto (2009) explicita que o leitor do livro é o mesmo da imagem e este pode ser o leitor das formas híbridas de signos e processos de linguagem, incluindo nessas formas até mesmo o leitor da cidade e o espectador de cinema, TV e vídeo. (SANTAELLA, 2011, p. 16)

É importante se ressaltar que, embora haja uma sequência histórica no aparecimento de cada um desses tipos de leitores, isso não significa que um mesmo leitor não possa ser classificado em mais de um tipo, vai depender do momento e da situação vividos por ele, ou seja, os tipos de leitores não são excludentes. Portanto, o que compete ao professor no caso do ensino da leitura é conhecer que tipo de leitor é o seu aluno e para quais tipos de leitura se sente estimulado.

\section{LEITOR PROFICIENTE}

Considerando que ler é uma atividade cognitiva e que a leitura é uma ação que exige operações mentais que vão, além da decodificação, a associação de várias informações. Assim, o leitor proficiente, na concepção de Mata (2015), é aquele que não só decodifica as palavras que compõem o texto escrito, mas 


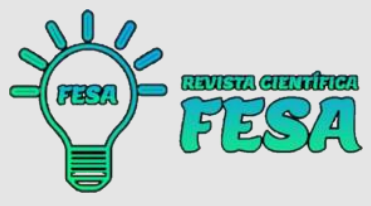

também constrói sentidos de acordo com as condições de funcionamento do gênero em foco, mobilizando, para isso, um conjunto de saberes (sobre a língua, outros textos, o gênero textual, o assunto focalizado, o autor do texto, o suporte, os modos de leitura). No processamento do texto, portanto, são articulados os elementos linguísticos que compõem a materialidade desse texto e o contexto de produção e de leitura.

Sobre isso, complementa Pelandré (2005, p. 91), citando que:

[...] a proficiência em leitura depende, ainda, de outras habilidades e conhecimentos, desenvolvidos em face precedente ao seu aprendizado. Depende da ampliação de vocabulário, da familiaridade com diferentes tipos de conversação, de habilidades de compreensão oral e de consciência metalinguística. Sobretudo, depende dos conhecimentos das convenções de que se faz uso o código escrito. (PELANDRÉ, 2005, p. 91).

Na leitura proficiente, ainda segundo Pelandré (2005, p. 93):

[...] interagem as representações fonológicas, ortográficas, sintáticas, lexicais (o ser humano possui uma espécie de dicionário interno, ou seja, um léxico), semântica e pragmática. Além dessas habilidades, o uso de estratégias que não são específicas da leitura, como as metacognitivas (planejamento, elaboração de hipótese, monitoração, inferência), complementa o processo, possibilitando a chegada ao que comumente se chama de leitura das entrelinhas. O que possibilita a interpretação de textos orais e escritos são os níveis mais altos de desenvolvimento intelectual (PELANDRÉ, 2005, p. 93).

Pelandré (2005, p. 94), ao tratar da importância da leitura na vida escolar, chama a atenção para as distintas funções sociais que exercem a leitura e a escrita do ponto de vista da comunicação ao afirmar que quem lê recebe os sinais luminosos emitidos pela folha que deverá processar até chegar ao sentido da macroestrutura, enquanto quem escreve deverá transformar o pensamento num texto escrito adequado ao leitor a quem se dirige.

O autor afirma ainda que, embora haja diferenças de natureza, função e de processamento entre leitura e escrita, ambas estão sempre correlacionadas, pois a leitura se faz de algo que foi escrito. Para escrever, o aprendiz tem de saber ler. Cita, por fim, que o ensino da escrita deve acontecer depois, ou, no mínimo simultaneamente ao da leitura, porque sem a leitura não há a construção da escrita. 
Outro aspecto referente à proficiência em leitura, de cunho mais técnico, é a questão do automatismo na aprendizagem da leitura como condição necessária para a proficiência em leitura. Acerca disso, segundo Scliar-Cabral (1989):

O leitor hábil, não tendo necessidade de refletir sobre os valores das letras, pode liberar sua atenção para processos mais criativos que constituem as atividades centrais da leitura (compreensão, interpretação, e retenção de informação nova e prazer estético. (PELÁNDRÉ, 2005, p. 105).

Ainda, segundo Pelandré (2005):

[...] os indivíduos não proficientes em leitura deixam de aplicar as regras do sândi, ou seja, [...] a leitura é feita palavra por palavra, ou sílaba por sílaba, quando em uma leitura proficiente as pausas são marcadas pelo sentido do texto. [...] Leitores menos proficientes utilizam com muita frequência seu conhecimento prévio para compensar suas dificuldades de decodificação, bem como as de retirada de informação do texto. Não utilizam, prioritariamente, a informação textual. (PELANDRÉ, 2005, p. 117).

Dando continuidade a seu pensamento, Pelandré (2005) reitera que, a leitura fluente requer o desenvolvimento de estratégias que vão além da decodificação e que dizem respeito à consciência metalinguística, por ser esta considerada uma das habilidades mais importantes no letramento. Há de se considerar, inclusive, que leitores e escritores proficientes, utilizam com mais propriedade conhecimentos metalinguísticos, monitorando o próprio ato de leitura e escrita empregando estratégias metacognitivas que visam facilitar o processo. (PELANDRÉ, 2005).

Para o aluno tornar-se proficiente em leitura, depende tanto da intensidade e do entusiasmo com que ele emprega essa habilidade, como também dos desafios a que deve ser submetido pelo professor. O teórico acrescenta, ainda, que quanto mais motivado for o indivíduo a ler e quanto mais leitura for feita, mais possibilidades de enriquecimento do léxico, de internalização de normas sintáticas, semânticas e pragmáticas. Somente, assim, por meio da leitura, podem ser adquiridos determinados conhecimentos que permitirão uma visão de mundo mais ampla.

Para tanto, a necessidade da leitura, como se apresenta, é condição essencial para o desenvolvimento da humanidade e está presente na história 


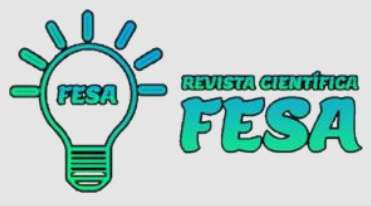

desde os tempos mais remotos até aos dias atuais. Assim como a noção de leitura, quase sempre associada à escrita, não aparece, portanto, como um ponto de vista unânime entre os pensadores, como visto por Manguel (1997, p.42) ao afirmar que também isso ocorre e que a leitura começa com os olhos.

Respaldam essa ideia os autores Sousa e Pereira (2014, p. 73), quando informam que:

[...] apenas para demonstrar como é antiga essa preocupação, lembramos que a maneira como o sujeito percebe o objeto é um gesto que já preocupava os antigos filósofos, dentre os quais Aristóteles (384 - 322 a.C.). Essa ainda é uma preocupação bastante atual, principalmente, do ponto de vista do ensino e da aprendizagem, a leitura permanece como uma temática tão presente. (SOUSA; PEREIRA, 2014, p. 73).

Seguindo essa linha de entendimento com relação à leitura, Freire (1989, p. 8) defende que o objeto da leitura é amplo, ou seja, é o mundo e a palavra, a leitura do mundo precede a leitura da palavra, daí que a posterior leitura desta não possa prescindir da continuidade da leitura daquele. Ainda, conforme Freire (1982), a leitura da palavra escrita apoia-se no conhecimento adquirido ao longo da vida, ao mesmo tempo em que amplia e modifica esse conhecimento.

Paralelamente, salientam Sousa e Pereira (2014, p. 70), que:

[...] o ato de aprender - conhecimento básico, elementar - primeiro no sentido da educação formal - nem sempre ocorre na escola. Pesquisas têm demonstrado que, numa sociedade como a nossa, rodeada de palavras escritas por todos os lados, o aluno, quando chega à escola, ainda que não decodifique as letras, já possui um conhecimento sobre os usos sociais da escrita, sabe, no mínimo, que existe o texto escrito e que ele é usado em várias situações do cotidiano dos sujeitos. Apesar disso, esse conhecimento, advindo da experiência cotidiana do aluno, nem sempre é levado em consideração pela escola". (SOUSA; PEREIRA, 2014, p. 73).

Pela sua importância, a leitura passa a ser uma atividade que deve ser estimulada, como propõe Antunes (2005, p. 19), ao postular que depois de ler uma crônica, não pare aí; leia outra, outras, muitas outras. O mundo imenso da leitura se descortina - é a revelação das palavras que vai provocar uma revolução na vida dos indivíduos; e é este o caminho para ampliar a capacidade leitora de jovens e adultos. 


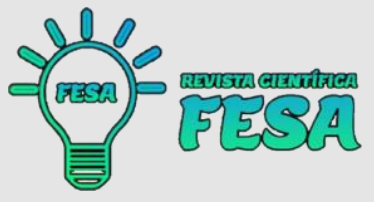

Diante desse contexto, pode-se observar que trabalhar as competências e habilidades dos estudantes em leitura, bem como o cuidado ao se avaliar esse domínio, têm sido uma das alternativas e preocupação de teóricos contemporâneos da área de educação, como menciona Soares (2011) ao relatar que:

[...] a questão da leitura no Brasil - (. . .) esteja ultrapassando as paredes da escola, saindo dos limites das discussões de educadores, e comece a aflorar na mídia e a tornar-se preocupação de outros profissionais, de políticos, de pais, é um bom sinal (tanto quanto possa ser "bom" um sinal de que a situação está chegando ao limite do tolerável e não pode mais ser ignorada). (SOARES, 2011).

Também é preocupação de instituições que apontam, através de avaliações aplicadas a alunos e escolas, informações importantes, resultando em estudos que podem ser utilizados pelos governos dos países envolvidos nesses sistemas de avaliação, como instrumento de trabalho na definição e refinamento de políticas educacionais.

\section{CONSIDERAÇÕES FINAIS}

O presente artigo teve como meta detalhar conceitos, concepções e ideias sobre leitura em prol de uma proficiência leitora. Para isso, consultaram-se obras de referência presentes em diversos indexadores, tais como a plataforma SciELO e a base de dados do Google Scholar. Percebeu-se, ainda, que a leitura não deve ser um ato realizado a esmo e sem conhecimento, tendo em vista a vasta teria que circunda as ações que convergem para o seu fomento.

Dessa forma, espera-se que tais escritos sirvam de base para trabalhos futuros que objetivem dar visibilidade para essa sensível problemática da leitura nos espaços escolares brasileiros, concedendo aos docentes novas formas de democratizar o acesso à leitura no Brasil.

\section{REFERÊNCIAS BIBLIOGRÁFICAS}

ADLER, M. J.; VAN DOREN, C. Como ler livros: O guia clássico para a leitura inteligente. (4⿳亠丷a reimpr.). São Paulo: É Realizações. 2015.

ANTUNES, W. de A. Revelação, revolução das palavras: Ampliando a capacidade leitora de jovens e adultos: guia de orientação de leitura e atividades. Brasília: Bibliofonte. 2005. 


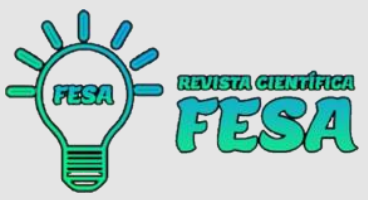

ANTUNES, W. de A. Biblioteca escolar: Curso de formação continuada de professores. São Paulo: Global. 2010.

ANTUNES, W. de A. Poder de irradiação. Revista Escola Pública, (18). 2010c

BELLO, A. História \& livro e leitura. Belo Horizonte, Autêntica. 2002.

BOZZA, S. Ler é a possibilidade de ir além é poder chegar a qualquer lugar sem precisar de avião ou de trem. Revista Aprendizagem, 2 (9), p.24. 2008.

CARNEIRO, L. A tecnologia como um elemento no estímulo à leitura. Recuperado de http://www.planetaeducacao.com.br/portal/imagens/artigos/educacaoetecnologiaBAURU\%20LUCIANA\%20Artigo\%20finalizado.pdf . 2008.

CANUTO, M. Três tipos de leitores: O contemplativo, o movente e o imerso. Recuperado de http://websmed.portoalegre.rs.gov.br/escolas/emilio/autoria/ artigos2009/artigo-mauricio-2009.pdf

Ferreiro, E. (2008). Valoriza as novas tecnologias. Recuperado de http://www.planeteeducacao.com.br/ambientevirtual/conteudo/conteudomensagem.asp?ID POSTAGEM=119\&siteArea=64\&assuntoid=41 . 2009.

FREIRE, P. A importância do ato de ler (23aㅡ ed.). Cortez: São Paulo. 1989.

PINA, F. H. Aprender a aprender. Santiago, Chile: Editorial Océano. 1998.

MANGUEL, A. Uma história da leitura. (2 $2^{\underline{a}}$ ed. E $6^{\underline{a}}$ reimp.) São Paulo: Companhia das Letras. 2010.

MATA, M. A. Leitor proficiente. Recuperado de http://ceale.fae.ufmg.br/app/webroot/glossarioceale/verbetes/leitor-proficiente . 2015.

MARTINS, A. Recanto do saber. Revista Nova Escola, 24 (221).

Recuperado de http://revistaescola.abril.com.br/planejamento-e-avaliacao/planejamento/recanto-saber-432175.shtml . 2009.

PELANDRÉ, N. Ensinar e aprender com Paulo Freire: 40 horas 40 anos depois (2a ed.). São Paulo: Cortez. 2005.

SALLA, F. Conclusões da área sobre como o cérebro aprende trazem à tona questões tratadas por grandes teóricos da Psicologia, como Piaget, 2012.

SANDOVAL, A. R. Desarrollo de hábito de lectura para hacer más eficientes las práticas pedagógicas y los aprendizajes de los estudiantes. 2008.

SANTAELLA, L. Navegar no ciberespaço: O perfil cognitivo do leitor imersivo. São Paulo: Paulus. 2011. 
SECCO, P. Amigos livros. São Paulo: Fundação Educar Dpaschoal. 2003.

SOARES, M. (2011). Ler, verbo transitivo. Recuperado de http://educarparacrescer.abril. com.br 2011.

SOUZA, M.; PEREIRA, R. Leitura e produção de texto I: Do texto para o mundo e do mundo para o texto: movimento de leitura e de escrita. Recuperado de http://www.cchla.ufpb.br/clv/images/docs/modulos/p1/p1 2.pdf .2014. 